\title{
Chemical Analysis of Solid Insulation Degradation using the AFM-IR Technique
}

DOI:

10.1109/ICD.2018.8514649

\section{Document Version}

Accepted author manuscript

Link to publication record in Manchester Research Explorer

\section{Citation for published version (APA):}

Rowland, S., Bastidas Erazo, P. D., Mcdonald, H., \& Morsch, S. (2018). Chemical Analysis of Solid Insulation Degradation using the AFM-IR Technique. In IEEE International Conference on Dielectrics IEEE.

https://doi.org/10.1109/ICD.2018.8514649

\section{Published in:}

IEEE International Conference on Dielectrics

\section{Citing this paper}

Please note that where the full-text provided on Manchester Research Explorer is the Author Accepted Manuscript or Proof version this may differ from the final Published version. If citing, it is advised that you check and use the publisher's definitive version.

\section{General rights}

Copyright and moral rights for the publications made accessible in the Research Explorer are retained by the authors and/or other copyright owners and it is a condition of accessing publications that users recognise and abide by the legal requirements associated with these rights.

\section{Takedown policy}

If you believe that this document breaches copyright please refer to the University of Manchester's Takedown Procedures [http://man.ac.uk/04Y6Bo] or contact uml.scholarlycommunications@manchester.ac.uk providing relevant details, so we can investigate your claim.

\section{OPEN ACCESS}




\section{Chemical Analysis of Solid Insulation Degradation using the AFM-IR Technique}

\author{
Harry McDonald, Pablo D. Bastidas, Simon Rowland \\ School of Electrical and Electronic Engineering \\ The University of Manchester \\ Manchester, United Kingdom \\ E-mail: harry.mcdonald@postgrad.manchester.ac.uk
}

\author{
Suzanne Morsch \\ Corrosion and Protection Centre, School of Materials \\ The University of Manchester \\ Manchester, United Kingdom
}

\begin{abstract}
To enable the continued development of power transmission cabling, an understanding of the processes which result in their failures is essential. In order to do so, powerful analysis techniques are required. However, those which consider chemical degradation are lagging behind those for visible degradation. This paper presents the Atomic Force Microscopy Infrared Spectroscopy (AFM-IR) chemical analysis technique, which can provide surface chemical analysis with resolution of $\sim 50 \mathrm{~nm}$ across the infrared spectrum. Two cases are considered: interfacial tracking between epoxy and silicone rubber, and the degraded region formed in front of a needle tip in the electrical tree initiation process. The results obtained using AFM-IR are compared to the outcomes from other techniques. It is found that AFM-IR offers a unique and powerful insight into visible and non-visible degradation of solid dielectrics.
\end{abstract}

Keywords-Electrical treeing, interfactial tracking, epoxy, AFM-IR, degradation, chemical analysis

\section{INTRODUCTION}

Polymeric materials such as XLPE are increasingly used in cable systems owing to their excellent breakdown strengths and dielectric properties. They are, however, vulnerable to a number of degradation mechanisms, among the most common of which are electrical treeing and interfacial tracking. Recently there has been extensive recent work in the study of visible aspects of degradation of dielectrics [1,2], with an aim of reducing cabling costs and improving asset management. However, the investigative tools for non-visible damage, such as chemical degradation, lack the same high resolution. This has limited the available evidence to guide the development of theories and models for the degradation processes. This paper presents a new method for the investigation of chemical degradation called Atomic Force Microscopy - Infrared Spectroscopy (AFM-IR) which can resolve down to $50 \mathrm{~nm} \mathrm{[3].}$

A degraded region has been found to develop around defects at high fields and this is generally taken to be the precursory step before tree and track initiation [4-6]. Associated studies have been largely limited to low oxygen environments [7] where aging is more pronounced. It has also been identified that degradation occurs within and around tree channels during their growth [8], however, the chemical pathways involved are again not yet known, limiting the understanding of the physical processes. An improved understanding of such process would inform the development of methods and materials to increase insulation resistance to aging and extend asset reliability.

To study localized chemical degradation on the scale of observed defects, more powerful investigative techniques are needed. While previous techniques have allowed limited characterization of the degradation, they lack the sensitivity and resolution to measure and localize chemical damage with the same spatial detail as has been achieved by imaging physical damage [1, 2]. Methylene blue dyeing has been utilized by Shimizu et al to identify and study the degraded region formed during low exposure to oxygen [7]. However, this does not provide a chemical characterization of the region. Fourier transform infrared spectroscopy (FTIR) and Raman spectroscopy were used by Uchida et al with the same aim, identifying an increase in $\mathrm{C}=\mathrm{C}$ and $\mathrm{C}=\mathrm{O}$ bonds [9]. These techniques have limited resolution of around $10 \mu \mathrm{m}$, due to the diffraction limit of IR light. Similarly $\mathrm{Hu}$ et al used microinfrared spectroscopy in the chemical study of tree channels [8]. Further methods have been used in the study of treeing and tracking, such as Electron Spin Resonance (ESR) and X-ray Photon Spectroscopy (XPS) [10]. However, none of these techniques has been able to combine the resolution achieved using the most recent imaging methods with the ability to clearly identify and distinguish the molecular damage in the polymer.

Analysis methods with resolutions in excess of a channel width are not sufficient to accurately study the inhomogeneous chemical degradation processes associated with treeing and tracking. Rather, they capture the bulk processes whilst failing to distinguish localized processes. AFM-IR, with an X-Y resolution of $50 \mathrm{~nm}$, is able to capture such variation in great detail and the method is presented here using the NanoIR2 system (Anasys Instruments). An interfacial tracking channel is analyzed [3] along with the degraded region around a needle tip immediately following electrical tree initiation.

\section{AFM-IR}

The AFM technique was developed in 1982 by IBM. This allowed topographical analysis at sub-nanometer resolutions. The later integration of infrared spectroscopy by Alexander Dazzi [11] supported surface-level chemical analysis. Utilizing an AFM probe cantilever, which is traced across the surface; 


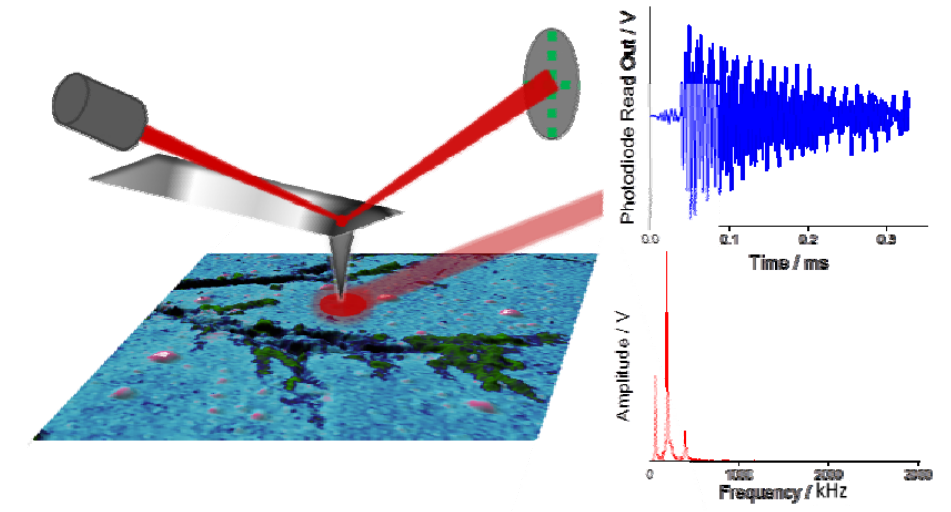

Fig. 1: AFM-IR experiment with top-down illumination. An IR source is pulsed, inducing rapid thermal expansion of the sample. This is detected by deflection of the AFM probe cantilever. The AFM-IR trace is recovered from fast Fourier transform of the deflection amplitude signal. [3]

subtle deflections due to height variations can be tracked to produce a 3D profile of the surface. A pulsed tunable top-down IR laser is used for the spectroscopy; when the wavelength of the beam corresponds to the excitation energy of chemical bond vibrations, this is accompanied by transient thermal expansion of the specimen. This expansion is then registered by the AFM probe and indicates the presence of such chemical bonds in that location. This measurement is carried out a number of times to allow for an average to be taken in that location and can be used to view the absorbance spectrum across the infrared range in that position, or to build high resolution chemical density mapping at a target wavelength. This process is illustrated in Fig. 1.

Whilst typical spectrographical methods are resolution limited by the diffraction limit, AFM-IR is able to overcome this limit by the use of an AFM probe. This allows the level of absorption across the surface area contacting the probe to be measured: approximately $50 \mathrm{~nm}$ in this experiment. Through this method the diffraction limit can be overcome and highly localized spectra can be determined. In samples in which large variations in chemical composition can be expected over small areas, this is a valuable tool and can provide crucial context to other chemical analysis methods. The AFM-IR technique has had previously demonstrated capability in the chemical characterization of epoxies [3, 12].

\section{Methodology}

\section{A. Interfacial Tracking Samples}

Interfacial tracks were generated between epoxy and vulcanized silicone rubber layers. The epoxy was prepared with Araldite-LY5052 and Aradur-HY5052 (Huntsman) in a 100:38 by weight mix. This was degassed for 50 minutes and cured in a $150 \mathrm{~mm} \times 50 \mathrm{~mm}$ x $5 \mathrm{~mm}$ (L x W x D) plaque for 24 hours at room temperature, then post-cured at $100^{\circ} \mathrm{C}$ for 4 hours. The silicone rubber layer (Polymax) was commercially acquired as a molded plaque.

A $45 \mu \mathrm{m}$ thick stainless-steel wire was used as an electrode defect, curved into a circle of diameter $1.2 \mathrm{~mm}$. This was placed between the epoxy and silicone rubber plaques with the air at the interface removed [13]. An AC voltage of $42 \mathrm{kV} \mathrm{rms}$ was applied to the steel wire for 1020 minutes. Interfacial tracks were thus generated, and monitored visually by camera and electrically by an Omicron MPD600 for partial discharge activity. The epoxy surface was then exposed by removing the silicone layer. As the tracks are evidenced by degradation of the exposed epoxy surface, they are able to be investigated using the AFM-IR technique.

\section{B. Electrical Treeing Samples}

The area at the tip of a metallic needle used in electrical tree growth experiments has been studied. A traditional needleplane sample was used. The same Araldite and Aradur composition used in the tracking tests was degassed for 70 minutes, and cured and post-cured similarly but using a $25 \mathrm{~mm}$ sided acrylic cube. Partway through the degassing process a needle (Ogura, $3 \mu \mathrm{m}$ tip radius) was inserted into the epoxy, with a $2 \mathrm{~mm}$ gap to the bottom/planar surface. This created a point-plane configuration allowing an $\mathrm{AC}$ voltage to be applied to the needle tip [14]. The applied voltage was steadily increased until tree initiation occurred (from $8.52 \mathrm{kV}$ to 10.35 $\mathrm{kV}$ rms over 19 minutes). This was monitored visually and electrically as with the tracking samples. On initiation of a tree the voltage was removed.

The region around the needle tip, the area of interest, is within the bulk of the material. This is in contrast to tracking along the surface, and so the region must first be exposed. In order to do this a cutting machine was used to remove most of the material, and the needle itself was then withdrawn. The samples were then carefully ground down until the desired point was exposed. This was done using polishing paper and a diamond compound paste $(3 \mu \mathrm{m}, 1 \mu \mathrm{m}$ and $1 / 4 \mu \mathrm{m})$ with visual inspections through a microscope to ensure the desired point was reached for chemical investigation with the AFM-IR.

\section{AFM-IR}

Following preparation, these sample surfaces were analyzed using the AFM-IR system, NanoIR2 (Anasys Instruments) in contact mode; the probe being traced along the surface. Scan rates of $0.04 \mathrm{~Hz}$ for the tracking samples and $0.08 \mathrm{~Hz}$ for the treeing samples were used, with a gold-coated silicon nitride probe, to produce the chemical map images. For the tracking samples, and with each excitation allowing a measurement, 32 co-averages were used for each point, of 


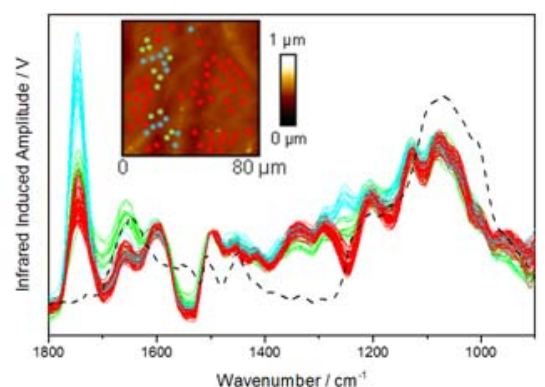

Fig. 2: AFM-IR spectra corresponding to locations indicated by markers on the contact mode height image (inset) of epoxy resin after 1020 minutes of electrical stress. Normalized to $1505 \mathrm{~cm}^{-1}$ peak. The dotted line shows ATRFTIR Spectrum. [3]

which there were 600 for each of 300 scan lines. For treeing samples, there were 16 co-averages for each point with 1024 points per line over 300 scan lines. Wider IR band spectra were produced at various points on the samples, and for each of these 1024 co-averages were used for each value.

\section{RESUlTS AND DiscUSSION}

In each case wideband spectral sweeps were performed at areas of particular interest, such that they could be compared to identify wavelengths, and potentially molecular densities, which were worth further investigation. This was followed by the production of chemical maps at specific wavelengths to see the variation in the absorption levels across the area.

\section{A. Interfacial Tracking Samples}

Full spectral sweeps were performed within and around the tracking channels. Fig. 2 shows the spectrum after 1020 minutes of aging at these different locations. The absorbance for each spectrum was normalized to $1505 \mathrm{~cm}^{-1}$. It reveals that the degradation products found inside the channel walls, and in the micrometers beyond it, have distinct differences.

- The strongest, most apparent signal was that of the peak at $1752 \mathrm{~cm}^{-1}$, attributed to $\mathrm{C}=\mathrm{O}$ stretch bonds. These were strongest within the channels (blue dots). This and a peak at $1248 \mathrm{~cm}^{-1}$ (C-O stretch) were taken as an indication of a large of concentration of esters within the channel.

- A distinct peak at $1660 \mathrm{~cm}^{-1}$ differed in that it was strongest just outside the channels (green dots) whilst the signal from within the channels is more similar to those further from the channels (red dots). This could indicate either a mechanism
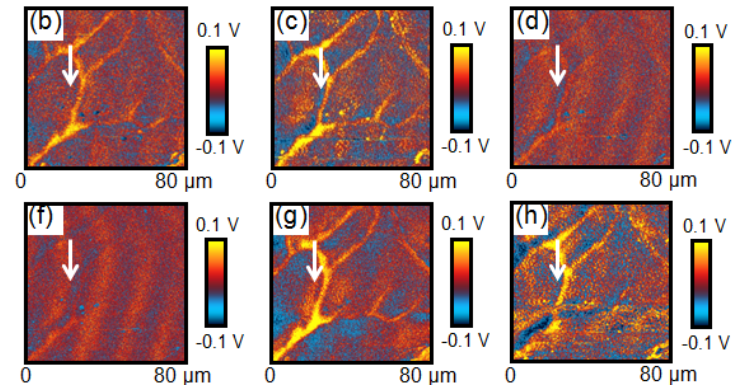

$0 \mu \mathrm{m}$ AFM-IR images of the epoxy resin surface after 1020 minutes of lectrical aging: (a) contact mode height image, and maps of the amplitude signal induced by ation at (b) $1080 \mathrm{~cm}^{-1}$; (c) $1248 \mathrm{~cm}^{-1}$; (d) $1336 \mathrm{~cm}^{-1}$; (e) $1456 \mathrm{~cm}^{-1}$; (f)

$1505 \mathrm{~cm}^{-1}$; (g) $1660 \mathrm{~cm}^{-1}$, and (h) $1752 \mathrm{~cm}^{-1}$ [3]

by which channels are able to widen, through degrading peripheral areas, or the transportation of degradation products into the bulk polymer following their generation.

- The red dots further from the channels still showed signs of degradation. In particular it was noted that $\mathrm{C}=\mathrm{O}$ and $\mathrm{N}-\mathrm{O}$ bond formation was indicated. That this occurs away from the channels indicates that either damage occurs distant from the visible defect, or there is transport of degraded materials into the bulk polymer.

The AFM-IR spectra are compared to an ATR-FTIR spectrum (dotted line) from the same sample in Figure 2, and this demonstrates the limitations of low resolution, wider volume scanning techniques. Here not only is much of the inhomogeneity of the sample lost, such as the differences in chemical compositions within and around the channels, but it is also apparent that the ATR-FTIR measurements were impacted by degradation products from below the surface, beyond the tracking channels. It is through using higher resolution methods in conjunction (such as the AFM-IR) that such differences can be discerned.

Following this, to better observe the changes across an area, chemical map images were produced at target wavelengths as can be seen in Fig. 3. These further confirmed the previous observations of ester carbonyl $(\mathrm{C}=\mathrm{O})$ absorbance increasing within the tracks and reducing in peripheral areas. Alkene absorbance $(\mathrm{C}=\mathrm{C})$ was found to increase around the outside of tracks but not inside them. Further, the generally decreased levels of $\mathrm{C}-\mathrm{O}, \mathrm{O}-\mathrm{H}$ and $\mathrm{N}-\mathrm{O}$ bonds indicate that these were the bonds being damaged during the degradation process.
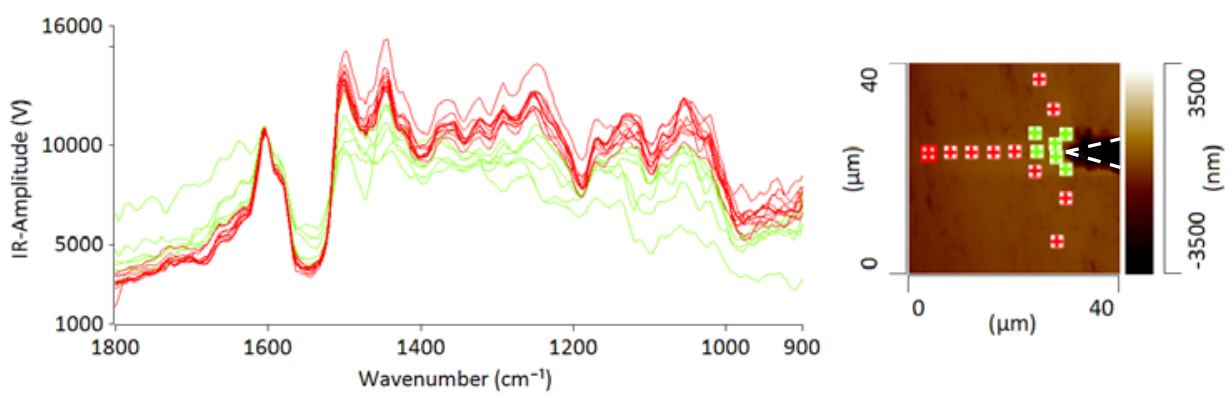

Fig. 4: AFM-IR spectra corresponding to tip locations indicated by markers on the contact mode height image (right) of epoxy resin following the initiation of an electrical tree from a needle tip. Spectra are normalized to $1600 \mathrm{~cm}^{-1}$ peak. Needle position shown by white dashed line. 


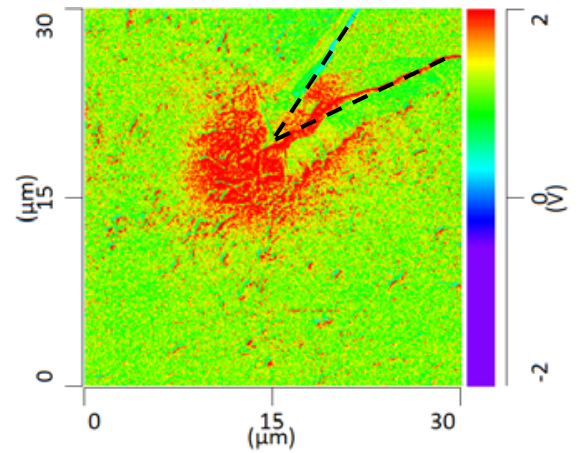

Fig. 5: $30 \mu \mathrm{m} \times 30 \mu \mathrm{m}$ AFM-IR map of surface at the $1708 \mathrm{~cm}^{-1}$ following tree initiation. Needle position shown by dashed lines.

\section{B. Electrical Treeing Samples}

A similar process of measurement and analysis was performed on the electrical treeing samples, looking at the degraded region beyond the needle tip immediately following tree initiation. The section analyzed in the sample described here did not include the tree channel. An initial spectral sweep, shown in Fig. 4, reveals a distinct increase in carbonyl $(\mathrm{C}=0)$ bonds in areas close to the needle tip, which is indicative of oxidation during the degradation process. Lower amounts of alkene $(\mathrm{C}=\mathrm{C})$ absorption were also detected.

Chemical maps were again produced to view wavelengths of interest. It can be seen from Fig. 5, looking at the $1708 \mathrm{~cm}^{-1}$ wavenumber, which can be considered an indicator of the presence of $\mathrm{C}=\mathrm{O}$ bonds, that the degraded region extends to roughly $8 \mu \mathrm{m}$ from the needle tip.

The observations here correlate well with previous findings on the degraded region, providing further confidence in the results and the method. Previous tests under low levels of oxygen had indicated that a region with greater densities of oxidized bonds would form at high voltages at high fields [7, 9]. The size of this region was typically found to be around 10 $\mu \mathrm{m}$, similar to that observed in this experiment. The use of the AFM-IR technique, with high sensitivity and resolution, is demonstrated here in a treeing sample immediately following initiation. This allows a detailed chemical analysis to be performed across the infrared spectrum with high resolution.

\section{CONCLUSION}

The capability of the AFM-IR in the study of degradation in solid dielectrics has been demonstrated, both as a stand-alone technique and as a worthwhile complement to other analysis tools. The application of this technique to both interfacial tracking and electrical treeing is discussed, looking at the visible, macroscopic tracking channels and the non-visible degraded region formed around a needle defect following tree initiation. With a resolution at submicron levels, the extent to which non-visible degradation products extend into the bulk material from a defect or channel can be observed, allowing details within this region to be clearly resolved far beyond the capabilities realized with previous techniques. This can be seen both through the wide-band spectra measured at key points and through the generation of chemical map images over an area. As well as this the low sampling depth ensures that chemical signals are taken from the intended surface locations only, minimizing signals from elsewhere.

\section{ACKNOWLEDGEMENTS}

McDonald is thankful for the financial support of the ESPRC through the Power Networks Centre for Doctoral Training. Morsch is grateful to AkzoNobel for financial support. Bastidas is grateful to EPSRC and The University of Manchester for a DTA grant.

\section{REFERENCES}

[1] R. Schurch, S. M. Rowland, R. S. Bradley, and P. J. Withers, "Imaging and analysis techniques for electrical trees using X-ray computed tomography," IEEE Transactions on Dielectrics and Electrical Insulation, vol. 21, no. 1, pp. 53-63, 2014.

[2] R. Schurch, S. M. Rowland, R. S. Bradley, and P. J. Withers, "Comparison and combination of imaging techniques for three dimensional analysis of electrical trees," IEEE Transactions on Dielectrics and Electrical Insulation, vol. 22, no. 2, pp. 709-719, 2015.

[3] S. Morsch, P. D. Bastidas, and S. M. Rowland, "AFM-IR Insights into the Chemistry of Interfacial Tracking," Journal of Materials Chemistry A, 2017.

[4] N. Shimizu, H. Katsukawa, M. Miyauchi, M. Kosaki, and K. Horii, "The space charge behavior and luminescence phenomena in polymers at 77 k," IEEE Transactions on Electrical Insulation, no. 5, pp. 256-263, 1979 .

[5] S. Bamji, A. Bulinski, and R. Densley, "Threshold voltage of luminescence and electrical tree inception in low-density polyethylene," Journal of applied physics, vol. 63, no. 12, pp. 5841-5845, 1988.

[6] N. Shimizu, K. Uchida, and S. Rasikawan, "Electrical tree and deteriorated region in polyethylene," Electrical Insulation, IEEE Transactions on, vol. 27, no. 3, pp. 513-518, 1992.

[7] N. Shimizu and K. Horii, "The effect of absorbed oxygen on electrical treeing in polymers," IEEE transactions on electrical insulation, no. 3, pp. 561-566, 1985.

[8] L. Hu, Y. Xu, X. Huo, and Y. Liao, "Chemical component analysis of electrical treeing in polyethylene by micro-infrared spectroscopy," IEEE Transactions on Dielectrics and Electrical Insulation, vol. 23, no. 2, pp. 738-747, 2016

[9] K. Uchida, H. Asai, N. Shimizu, and T. Takahashi, "Initiation mechanism of electrical tree and deteriorated region in polymers," in Properties and Applications of Dielectric Materials, 1991., Proceedings of the 3rd International Conference on, 1991, pp. 240-243: IEEE.

[10] K. Kaminaga, T. Suzuki, T. Uozumi, T. Haga, N. Yasuda, and T. Fukui, "The mechanism of degradation of polyethylene in a high electrical field," in Electrical Insulation and Dielectric Phenomena, 1993. Annual Report., Conference on, 1993, pp. 666-671: IEEE.

[11] A. Dazzi, C. B. Prater, Q. Hu, D. B. Chase, J. F. Rabolt, and C. Marcott, "AFM-IR: combining atomic force microscopy and infrared spectroscopy for nanoscale chemical characterization," Applied Spectroscopy, vol. 66, no. 12, pp. 1365-1384, 2012.

[12] S. Morsch, Y. Liu, S. B. Lyon, and S. R. Gibbon, "Insights into epoxy network nanostructural heterogeneity using AFM-IR," ACS applied materials \& interfaces, vol. 8, no. 1, pp. 959-966, 2015.

[13] P. D. Bastidas and S. M. Rowland, "Interfacial aging in composite insulators as a result of partial discharge activity," in Electrical Insulation Conference (EIC), 2017 IEEE, 2017, pp. 13-16: IEEE.

[14] J. H. Mason, "Assessing the resistance of polymers to electrical treeing," Physical Science, Measurement and Instrumentation, Management and Education - Reviews, IEE Proceedings A, vol. 128, no. 3, pp. 193-201, 1981. 